\title{
Water-quality variability in dryland riverine waterholes: a challenge for ecosystem assessment
}

\author{
Carrie K. Preite† and Richard G. Pearson* \\ College of Science and Engineering, James Cook University, Queensland 4811, Australia
}

Received 13 December 2016; Accepted 27 March 2017

\begin{abstract}
Waterholes in intermittent dryland rivers are important biotic refugia, but detailed water-quality descriptions of these habitats are rare. Their possible variability in water quality, due to variable flow regimes, may impede development of appropriate water-quality guidelines. We investigated this issue by describing spatial and temporal variation in water quality in waterholes in a tropical Australian dryland system. Water quality varied considerably among three rivers, between sites within rivers and within sites, reflecting lithology, hydrology, bathymetry, local catchment influences, stratification and within-site patchiness. Seasonal variation was due to differences in insolation, temperature, flow and depth. Diel variation was high for $\mathrm{pH}$ and dissolved oxygen (DO) at some sites. Variation among locations within waterholes was low for $\mathrm{DO}$, temperature and $\mathrm{pH}$, but higher for chlorophyll and nutrients, due to shade-related patchy photosynthesis. Neither the rivers nor the waterholes within them could indicate water-quality reference conditions because of their different characteristics. Our results highlight the need for strategic timing and location of sampling to capture spatial and temporal variation in key water-quality variables and to identify critical ecological conditions in dryland riverine waterholes.
\end{abstract}

Key words: River health / monitoring / dissolved oxygen / Australia / tropics

\section{Introduction}

Water quality encompasses many biophysical variables that are the essential descriptors of environmental conditions required to ascribe cause-effect ecological relationships. Addressing spatial and temporal variability of water quality is necessary in sampling program design to ensure capture of critical values and times, but can be difficult, given the many interacting variables (Bunn et al., 2010). Information is especially needed for waterbodies that have received limited attention (Davis et al., 2016), such as the intermittent river systems that dominate aquatic habitats in the extensive dry tropics globally. In tropical Australia, for example, many rivers persist in the dry season as a series of disconnected waterholes (Wallace et al., 2015) because rainfall is highly seasonal or sporadic (Brodie and Mitchell, 2005). Nevertheless, large amounts of water can be seasonally available, creating interest in agricultural development beyond the usual pastoralism. Rivers and permanent waterholes can provide critical habitats and

*Corresponding author: richard.pearson@jcu.edu.au $\dagger$ Present address: Dr C.M. Preite, Department of Biological Sciences, College of Southern Nevada, Las Vegas, NV 89030, USA drought refugia for biota (Bunn et al., 2006; Sheldon et al., 2010), and a water source for terrestrial wildlife (Pettit et al., 2012; Wallace et al., 2015). Therefore, there is a need to be able to assess aquatic health in these systems, including the spatial and temporal variability of biophysical characteristics.

Understanding of the ecology of dryland rivers is advancing (e.g., Leigh and Sheldon, 2009; Sheldon et al., 2010; Blanchette and Pearson, 2012a, b; Pettit et al., 2012; McJannet et al., 2014; Davis et al., 2016), but detection of critical water quality maxima or minima across spatial and temporal scales is logistically challenging and may be rarely achieved (e.g., Marshall et al., 2006). The nature of riverine waterholes can vary substantially, often depending on local environmental factors rather than catchment condition (Sheldon and Fellows, 2010; Blanchette and Pearson, 2012a). Our inadequate knowledge of variability from small to larger spatial and temporal scales limits our understanding of the intensity and timing of sampling required to provide adequate description of these systems.

We aimed to understand variation in water quality in riverine waterholes as a corollary to ecological studies, and to determine an optimum sampling regime. We described the variability of selected water-quality parameters in waterholes of a large system draining into the Great 


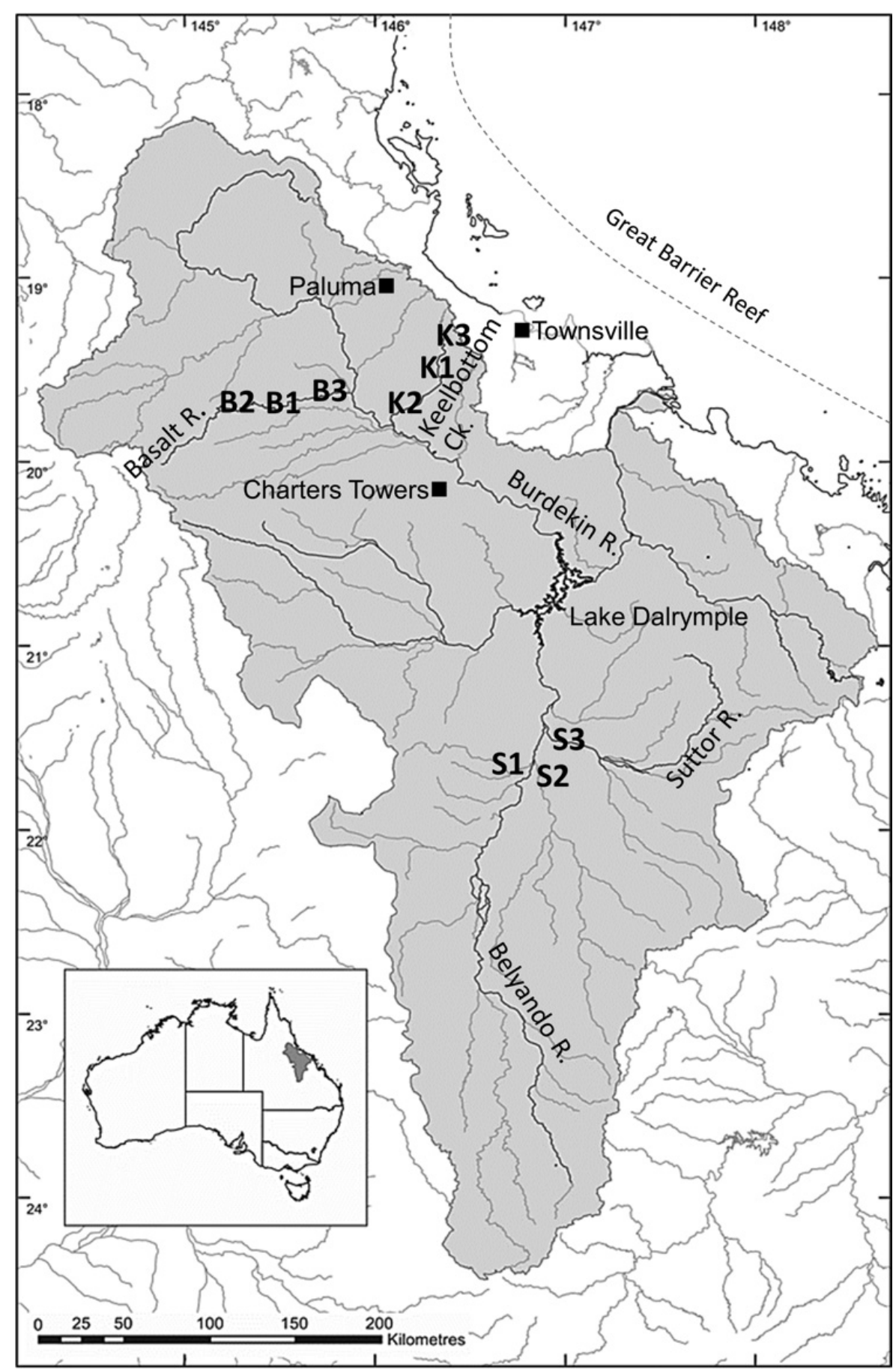

Fig. 1. Locations of the Burdekin catchment in northeastern Australia, of places mentioned in the text, and of sampling sites on the Basalt (B1-3) and Belyando/Suttor rivers (S1-3) and Keelbottom Creek (K1-3).

Barrier Reef lagoon (GBR), in northeastern Australia. We tested the predictions that water quality would be influenced by catchment and local characteristics, smallscale patterns within waterholes, and temporal change at seasonal and daily scales (Davis et al., 2016). It was expected that the seasonal tropical climate would be reflected in the water quality of the waterholes, which would diverge in character according to local factors when flow ceased (Sheldon and Fellows, 2010; Blanchette and Pearson, 2012a).

\section{Methods}

\section{Study area and sites}

We sampled waterholes in three tributaries of the Burdekin River across several spatial and temporal scales. The Burdekin River rises to the west of the coastal mountains in northeastern Queensland, and has major tributaries joining from the west, south and southeast (Fig. 1). It has a catchment area of $136000 \mathrm{~km}^{2}$ 


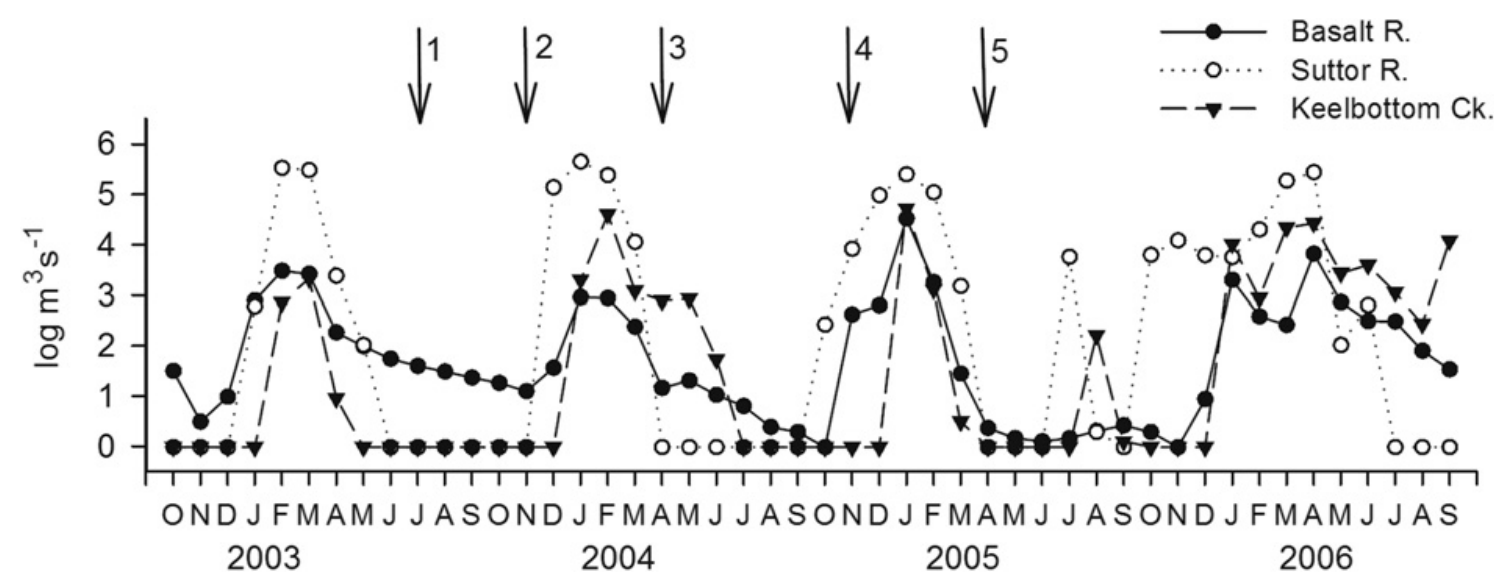

Fig. 2. Monthly flows (log scale) in 2003-2006 in the Basalt River (site B2), Keelbottom Creek (site K3) and Suttor River (site S3). Arrows show sampling times for survey 1: 1, July 2003, 2, November 2003 and 3, April 2004; and survey 2: 4, November 2004 and 5, April 2005.

(QDNRM, 2002) and is about $900 \mathrm{~km}$ long. The climate of the area is seasonal "wet-dry" tropical, with monthly mean temperature range at Charters Towers of $17.3-27.4^{\circ} \mathrm{C}$. Mean annual precipitation is $659 \mathrm{~mm}$ at Charters Towers, but is higher in the coastal mountains (2656 mm at Paluma) (Australian Bureau of Meteorology data), and is seasonally and annually highly variable, as are river flows (Fig. 2). Peak flows occur in the December-April wet season and decline in the dry season, May-November, during which many tributaries cease to flow (Kennard et al., 2010; Blanchette and Pearson, 2012a; Davis et al., 2016).

Catchment lithology includes basaltic and sedimentary formations, large areas of granite and granodiorite, and alluvial deposits. The landscape comprises mainly semi-arid woodlands and grasslands, but includes some tropical rainforest in the mountains (e.g., Paluma, Fig. 1), and a large floodplain and delta. Land use includes cattle grazing ( $96 \%$ of the catchment), irrigated cropping on the floodplain $(\sim 2 \%)$, and national parks and state forest ( $2 \%$ ) (QDNRM, 2002). The river is of management interest as a source of water for irrigation and because of its large input of sediment into the GBR (McKergow et al., 2005).

We selected three permanent riverine waterholes on each of the Basalt River, Keelbottom Creek and Suttor River (including Belyando River) (Fig. 1). The rivers had contrasting biophysical characteristics, including flow regime (Fig. 2), but the sites within them were generally similar (Table 1). The Basalt River has mostly perennial flows, derived from basaltic aquifers, with sparse riparian vegetation and aquatic macrophytes along the water's edge. Keelbottom Creek had no surface flow during the dry season, with dense riparian woodland and abundant aquatic macrophytes ( $\geq 50 \%$ cover). The Suttor River had no surface flow during the dry season, moderately dense riparian woodland, no aquatic macrophytes and turbid water. Low densities of cattle accessed all sampling sites.

\section{Sampling program}

In survey 1 , we sampled the nine sites in the mid-dry, late-dry and post-wet seasons (July, November and April, respectively; Fig. 2), at approximately 06:00, 11:30 and 16:00 $\mathrm{h}$ on a single day at each site, during dry weather (no rainfall for $\sim 30$ days before and during sampling). Sunrise and sunset times at nearby Charters Towers were, respectively, 06:50-17:51 for July, 05:27-18:32 for November and 06:25-18:03 for April. We focused on variables that are readily measured in situ, and are important in biological processes (Butler et al., 2009). Measurements were made from a boat in open water and among aquatic macrophytes (if present). Photosynthetically active radiation (PAR) was measured with a Li-Cor LI-250 m, and water temperature, conductivity, dissolved oxygen (DO) and $\mathrm{pH}$ were measured using a YSI 556 instrument. All measurements were made in the water column at $25 \mathrm{~cm}$ depth and then at $1.0-\mathrm{m}$ intervals to the bottom of the water body. The design was 3 seasons $\times 3$ rivers $\times 3$ sites $\times 2$ habitats $\times 3$ times of day $(N=162), \times 2-8$ depths, as available.

In survey 2 , we sampled at a single site on each river in the late-dry and post-wet seasons (November, April; Fig. 2), but with more samples than in survey 1 , and inclusion of major nutrients. In situ measurements were recorded as previously at multiple depths for 3 days at dawn and mid-day at six open-water locations within each waterhole. Composite 10-L water samples for nutrient analysis were collected on day 3 at dawn and mid-day from three of the six locations, using a Solinst 410 peristaltic pump, by steadily raising the pump inlet pipe from bottom to surface, avoiding sediments. We used composite samples for logistic reasons (storage of multiple samples; cost). Subsamples of $1.0-\mathrm{L}$ were placed on ice in the dark and were returned to the laboratory for analysis of chlorophyll, phaeophytin $a$, nutrients and turbidity. The survey 2 design for $i n$-situ variables was 2 seasons $\times$ 3 rivers $\times 1$ site $\times 3$ days $\times 2$ times $\times 6$ replicates, 


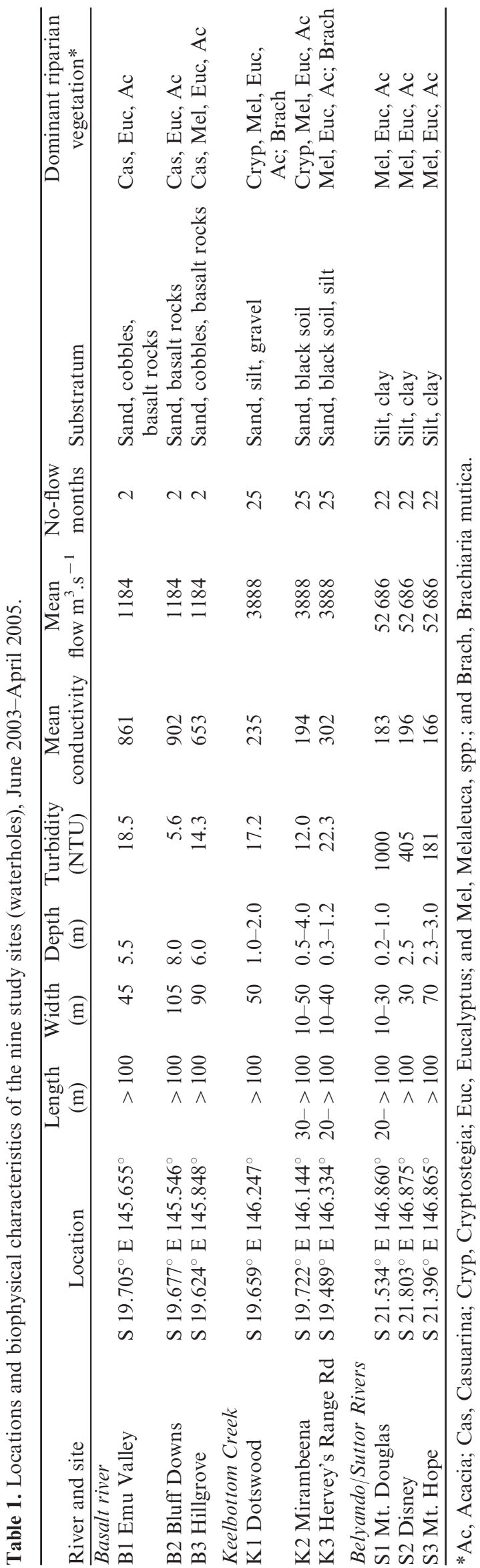

$N=216 \times 2-8$ depths; and for nutrients, 2 seasons $\times$ 3 rivers $\times 1$ site $\times 1$ day $\times 2$ times $\times 3$ replicates, $N=36$.

\section{Water analysis}

Turbidity was measured in a calibrated glass vial using a HACH 2100P turbidimeter. For determination of chlorophyll $a, b$ and $c$, and phaeophytin $a$ concentrations water samples were filtered on a Whatman GF/B $47 \mathrm{~mm}$ glass microfibre filters $(0.7 \mu \mathrm{m}$ pore size $)$ using a glass vacuum filter, then determinations were made following Jeffery and Humphrey (1975); chlorophyll values were subsequently summed for statistical analysis. Samples for nutrient analysis were similarly filtered, with particulate material digested by persulphate digestion. Filtrate and digested nitrogen $(\mathrm{N})$ and phosphorus $(\mathrm{P})$ were analysed using an OI Analytical Alpkem Segmented Flow Analyzer to determine concentrations of particulate nitrogen and phosphorus, and nitrate $\left(\mathrm{NO}_{3}-\mathrm{N}\right)$ and filterable reactive phosphorus (FRP).

\section{Statistical analysis}

Parameters were firstly separated into those that were likely most affected at the catchment scale by lithology and soil (conductivity and turbidity) and the rest, which were likely to be most affected by local influences; $\mathrm{pH}$ could reflect either scale, and was grouped with the local-scale variables. Multivariate analyses were undertaken on normalized data in PRIMER ${ }^{\circledR}$ version 6 (Clarke and Gorley, 2006). Patterns among sites, samples and sample groups were described using Principal Component Analysis (PCA) based on Euclidean distance, with the strength of the relationships between water-quality variables and PC-axis scores indicated by Pearson correlation coefficients and differences between groups tested using analysis of similarities (ANOSIM). Contrasts among samples were investigated using permutational MANOVA and ANOVA (PERMANOVA version 1 - Anderson et al., 2008), using Euclidean distance, 999 permutations, and nested designs, the null hypotheses being that there were no differences among designated groups of samples. We undertook regression analyses of local-scale against catchment-scale variables in SigmaPlot ${ }^{(\mathrm{c})} 12.5$, and we used distance-based linear modelling (DistLM) in PRIMER to determine catchment influence on local water quality.

\section{Results}

Plots of survey 1 data illustrate the variation within sites and times, and among sites, rivers and seasons (Fig. 3). Temperatures did not vary greatly between seasons at each site, and varied more between sites within each river. Variation in temperature within sites and months, and across sampling times and depths (i.e., within each box/whisker in Fig. 3) differed substantially between 

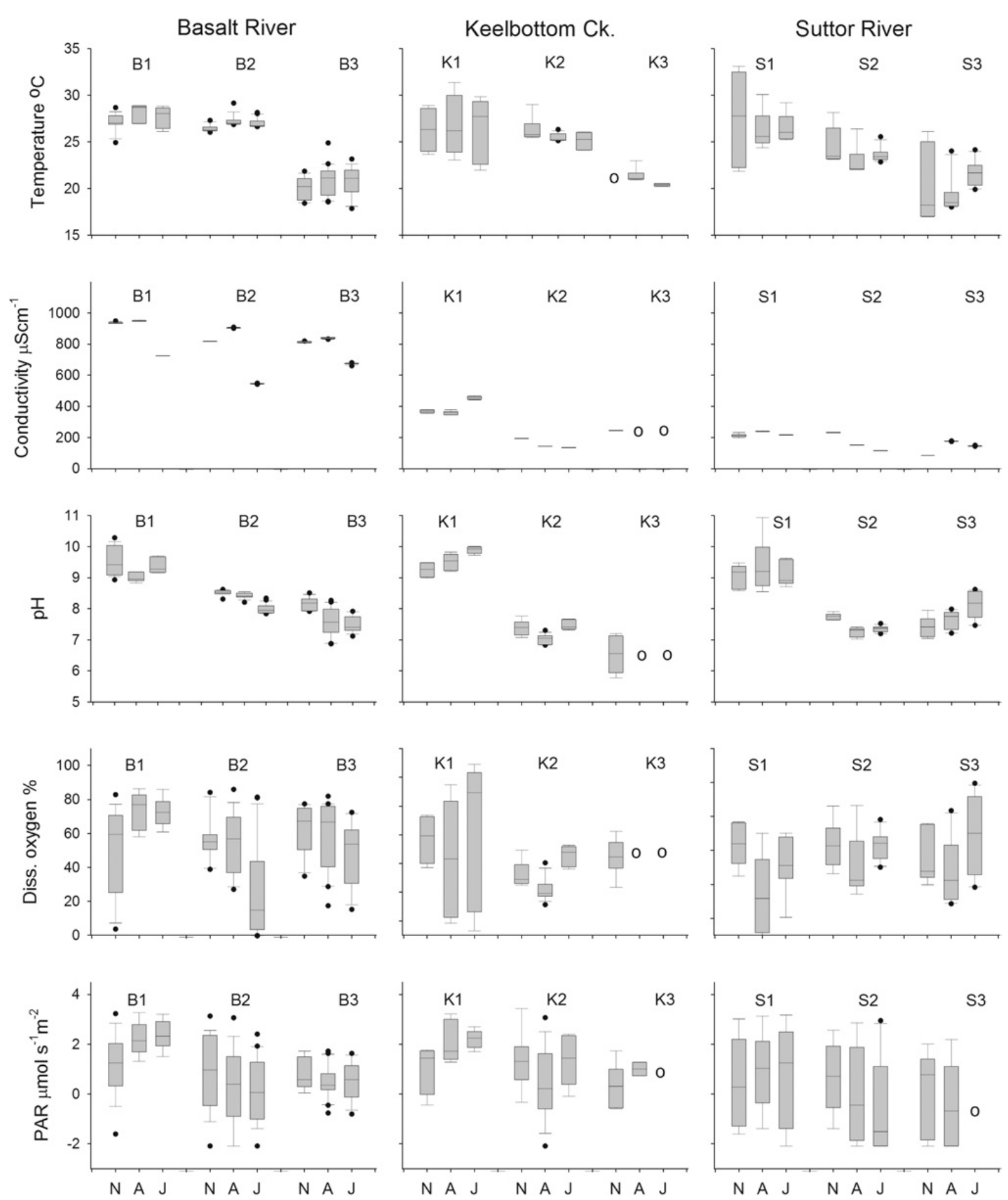

Fig. 3. Boxplots summarizing water-quality data from survey 1 showing, from top to bottom, variability in temperature, conductivity, $\mathrm{pH}$, dissolved oxygen and PAR due to depth and time of day within sites/months and among sites, rivers and seasons. Plots include median value (horizontal line), 25th and 75th percentiles (shaded box), 10th and 90th percentiles (whiskers) and 5th and 95th percentiles (dots), based on measurements at multiple depths and times. Sites are labelled according to River (B, Basalt; K, Keelbottom; S, Suttor) and site number. Samples are from November, April and July (N, A, J). "o" indicates missing data due to instrument malfunction.

sites, particularly the shallow sites $\mathrm{S} 1$ and $\mathrm{S} 3$ in November. Deep sites (e.g., B2) and shaded sites (e.g., K3) showed very low diel/depth variation.
Conductivity was higher in the Basalt than the other rivers, and had very little diel or depth variation across seasons, rivers and sites. $\mathrm{pH}$ showed diel/depth variation 

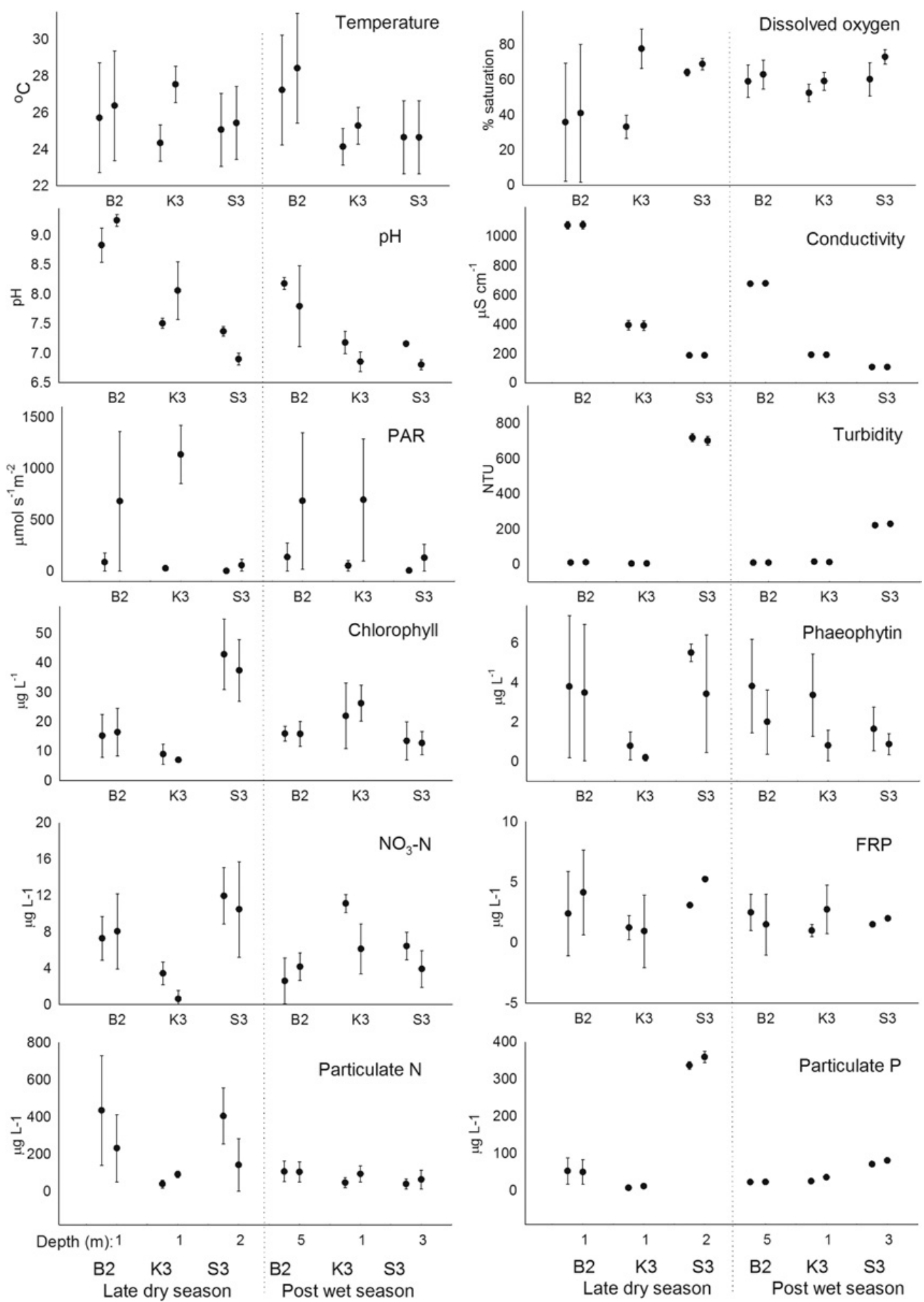

Fig. 4. Summary of water-quality data from single sites in three rivers in survey 2 (B2, K3 and S3 represent sites on the Basalt River, Keelbottom Creek and Suttor River, respectively). Twin bars represent samples from dawn and midday. Bars represent variation (minimum-maximum) with depth and spatial replication.

up to 2 units at some sites/months, but was less variable at other sites (e.g., B2 and S2). There was no common pattern among sites even within rivers. DO was variable within sites/months and among months, sites and rivers, with some sites varying up to about $90 \%$ saturation by depth and/or time of day (e.g., K1). Variation was not consistent even within rivers. PAR was variable within sites/months, partly reflecting diel changes in insolation and turbidity.

Plots of survey 2 data illustrate similar variation of the variables measured in situ within sites by depth (error bars) and times (paired bars), and among sites, rivers and seasons (Fig. 4). The chlorophyll concentration was highest at site S3 in the late dry season and at site $\mathrm{K} 3$ in 


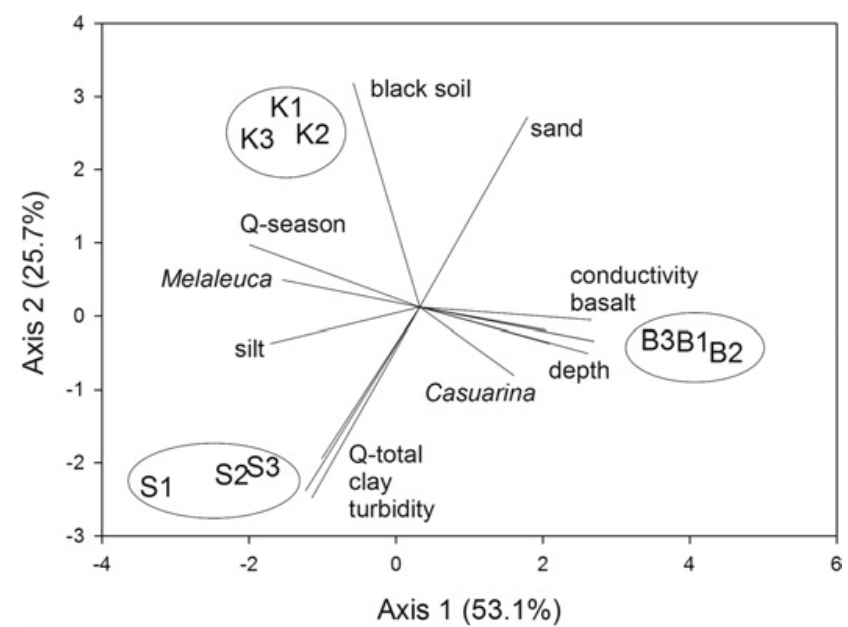

Fig. 5. PCA ordinations of sites by broad biophysical characteristics with vectors, showing the variables correlating most strongly with axes. Locations of sites in ordination space are indicated (B1-3, K1-3, S1-3), as is the \% variance explained by each axis. Q-season represents $\mathrm{CV}$ of monthly flows and Q-total represents total annual flow.

the post-wet season; it varied substantially with depth. Phaeophytin concentrations varied considerably within sites except $\mathrm{K} 3 . \mathrm{NO}_{3}-\mathrm{N}$ was variable within sites, and lowest at site $\mathrm{K} 3$ in the late dry season, but highest at site $\mathrm{K} 3$ in the post-wet season. FRP was variable within sites, but similar between sites. There was a strong correlation between chlorophyll concentration and $\mathrm{NO}_{3}-\mathrm{N}\left(r_{11}=0.853, P<0.001\right)$ but not FRP $\left(r_{11}=0.323, P=0.283\right)$. Particulate $\mathrm{N}$ concentration was high and variable at sites B2 and S3 in the late dry season, but much less so in the post-wet season. Particulate $\mathrm{P}$ concentration was high at site $\mathrm{S} 3$ in the late dry season.

PCA of broad biophysical characteristics separated rivers, but tightly grouped sites within rivers (Fig. 5), with axes strongly correlating with flow seasonality (CV of monthly flows), conductivity and riparian vegetation (axis 1), and annual total flow, substratum and turbidity (axis 2). PCA of survey 1 water-quality data indicated separation of seasons on axis 1, of Keelbottom Creek and Suttor River on axis 1, and of Basalt River on axis 2 (Fig. 6); ANOSIM confirmed the overall separation of samples by season and river and indicated pairwise differences between seasons and between rivers (online Table S1). Axis 1 was associated most strongly with conductivity, $\mathrm{pH}$, temperature and PAR (all positive); axis 2 with conductivity (positive), and turbidity and chlorophyll concentration (negative) (Fig. 6; online Table S2).

PCA of survey 2 data indicated separation of seasons for Keelbottom and Suttor sites, but not for the Basalt River, and strong separation of the three rivers (Fig. 6); again, ANOSIM confirmed the overall separation of samples by season and river (online Table S1). Axis 1 was largely associated with temperature, $\mathrm{pH}$, conductivity and PAR (all positive) and minimum DO (negative); axis 2 was largely associated with turbidity, $\mathrm{NO}_{3}-\mathrm{N}$, particulate $\mathrm{N}$ and $\mathrm{P}$, and chlorophyll (all positive) (online Table S2).

PERMANOVA confirmed major contrasts at the levels of season and river, and also demonstrated contrasts among sites, habitat and time, in minimum temperature, DO, $\mathrm{pH}$, conductivity, turbidity and concentrations of phaeophytin and chlorophyll (online Table S3). Temperature, DO and PAR differed substantially among depths, and particulate $\mathrm{N}$ and $\mathrm{P}, \mathrm{NO}_{3}-\mathrm{N}$ and FRP varied among seasons and rivers. Pairwise comparisons of survey 2 data using PERMANOVA show major contrasts among most pairs of seasons, rivers and times of day in temperature, DO, $\mathrm{pH}$, conductivity and PAR, except for contrasts in turbidity and conductivity with time of day (online Table S3). Contrasts between depths in temperature, DO and PAR were all significant, as were $50 \%$ of conductivity comparisons, but none of the $\mathrm{pH}$ comparisons. Turbidity and chlorophyll differed between seasons as did some or most comparisons of phaeophytin, particulate $\mathrm{N}$ and $\mathrm{P}, \mathrm{NO}_{3}-\mathrm{N}$ and FRP. Turbidity, particulate $\mathrm{N}$ and $\mathrm{P}, \mathrm{NO}_{3}-\mathrm{N}$ and FRP differed between rivers, but chlorophyll and phaeophytin did not. Turbidity, chlorophyll, phaeophytin, particulate $\mathrm{N}$ and $\mathrm{P}, \mathrm{NO}_{3}-\mathrm{N}$ and FRP did not differ between times of day. We could not determine any nutrient relationships with depth because samples were composites from the water column.

Daily variation in survey 2 reflected the dawn, midday and late afternoon sampling regime (Fig. 7). Stratification in temperature was not great, varied with time of day, and was greatest in the Suttor River. DO stratified in the Basalt River in April and in the Suttor River in November. PAR was stratified as light attenuated with depth in the Basalt River and in the turbid Suttor River. The Basalt River, being the least shaded and least turbid river, had the highest diel variation, especially at depths $>1 \mathrm{~m}$.

Variability among spatial replicates in survey 2 was low for temperature, $\mathrm{pH}$ and conductivity, with $\mathrm{DO}$ somewhat more variable (Table 2). PAR, chlorophyll, particulate $\mathrm{N}$ and $\mathrm{NO}_{3}-\mathrm{N}$ showed greatest variability among replicates, probably reflecting variable shade across waterholes. Maximum and minimum values for in situ variables demonstrate a wide range over the sampling program (Table 2). Most notable are the values for DO, ranging from extreme hypoxia to supersaturation $(0.7-133.5 \%), \mathrm{pH}$ ranging from mildly acid to highly basic (5.8-11.0), and PAR, ranging from close to 0 to $2221.0 \mu \mathrm{mol} \mathrm{m}^{-2} . \mathrm{s}^{-1}$.

Regression analyses identified relationships between putative broad-scale variables (conductivity and turbidity) and other water-quality variables (Table 3; online Supplementary Figs S1 and S2). In Survey 1, changes in conductivity correlated with $\mathrm{pH}$ (explaining up to $17 \%$ of the variance, but only $4 \%$ of the variance in $\mathrm{pH}$ range), turbidity (11\%), chlorophyll (12\%) and phaeophytin (9\%). Turbidity correlated with chlorophyll $(26 \%)$ and phaeophytin (14\%). Linear modelling indicated a very modest effect of conductivity $(6.5 \%)$ and turbidity $(4 \%)$ on overall water quality. In survey 2 , conductivity correlated with particulate $\mathrm{N}(11 \%), \mathrm{NO}_{3}-\mathrm{N}(16 \%)$ and particulate $\mathrm{P}(14 \%)$; and turbidity correlated with 

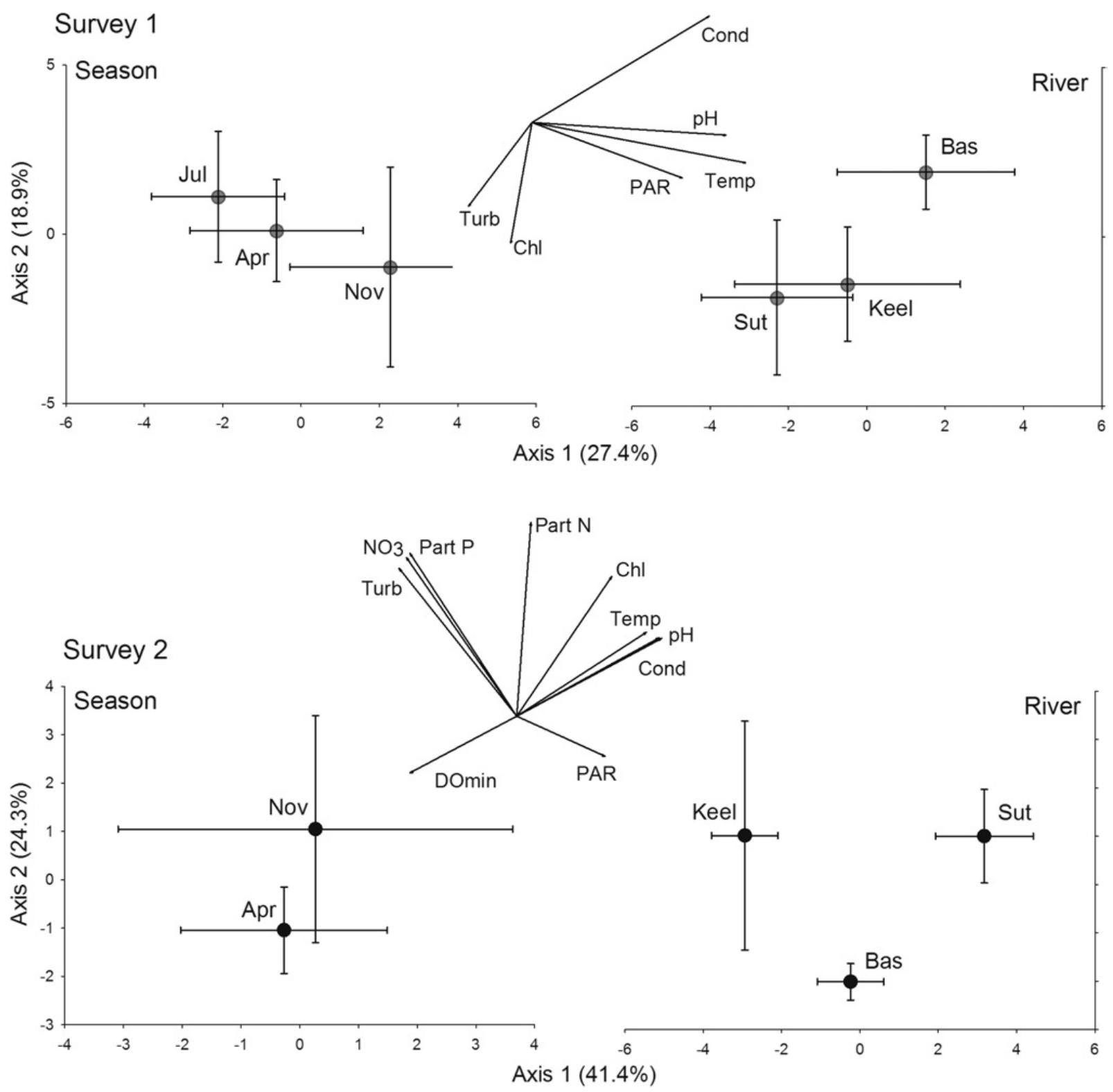

Fig. 6. PCA ordinations of water-quality samples from surveys 1 (upper panels) and 2 (lower panels), showing distribution of samples (centroids \pm SD) grouped by season (left panels: November, April, July) and river (right panels: Basalt River, Keelbottom Creek, Suttor River). Central vector plots show variables that correlate most strongly with the axes $(P<0.05$; see online Table S2). The \% variance explained by each axis is shown. All groups and pairs of rivers or season differed significantly (ANOSIM; see online Table S1).

particulate $\mathrm{N}(18 \%), \mathrm{NO}_{3}-\mathrm{N}(98 \%)$, particulate $\mathrm{P}(97 \%)$ and FRP $(13 \%)$. Linear modelling indicated a small effect of conductivity (11\%) and strong effect of turbidity (57\%) on overall nutrient status.

\section{Discussion}

There was no common pattern in water quality among sites even within rivers. Water quality varied among the three rivers, between sites within rivers and within sites, reflecting differences in lithology (represented by conductivity, turbidity and $\mathrm{pH}$ ), hydrology (flow regime), bathymetry, local influences (e.g., stratification, shade), and within-site patchiness (e.g., shade). DO in particular was variable within sites/months and among months, sites and rivers, with some sites varying up to about $90 \%$ saturation by depth and/or time of day. PAR, chlorophyll, particulate $\mathrm{N}$ and $\mathrm{NO}_{3}$ showed greatest within-site variability, reflecting patchy shade across waterholes. Seasonal variation was due to differences in insolation, ambient temperature, flow and depth. Nevertheless, variation was less than in smaller, drying waterholes (Wallace et al., 2015).

Our data support a recent model for dryland rivers (Davis et al., 2016), in which: (i) declining dry-season flow leads to loss of connectivity, stratification and increasing importance of local influences; (ii) first rains 

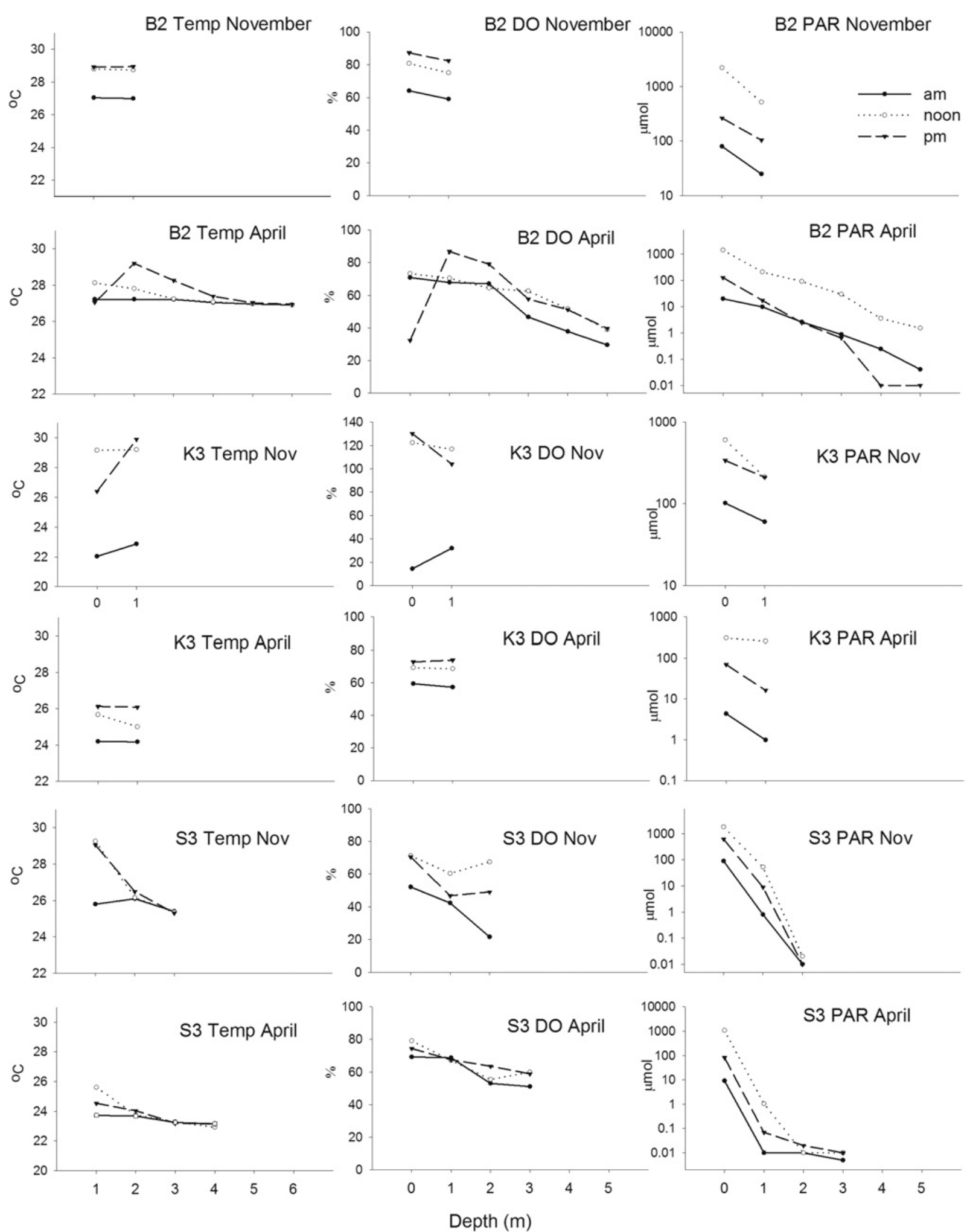

Fig. 7. Variation in water quality by time of day (a.m., noon, p.m.) and stratification by depth ( $X$-axis) at three sites (B2, K3 and S3) in November (Nov) and April. Left-hand panels show temperature (Temp, ${ }^{\circ} \mathrm{C}$ ), central panels show dissolved oxygen (DO, \% saturation) and right-hand panels show PAR $\left(\mu \mathrm{mol} \mathrm{s}{ }^{-1} . \mathrm{m}^{-2}\right)$.

of the wet season cause "pre-flush" inputs of local contaminants (e.g., cattle faeces) and mixing of hypoxic water; and (iii) strong wet-season flows reconnect and flush waterholes, resetting the system. Sheldon (2005) described similar but more extreme events for inland Queensland systems, which had less prolonged flow than 
Table 2. Summary of spatial variability (A) and extreme values (B) in water quality across sites. (A) shows frequency (\%) of different levels of coefficient of variation (CV \%) among spatially replicated samples of water-quality variables from survey 2. (B) shows minima (Min) and maxima (Max) of water-quality variables in each river during the two surveys.

\begin{tabular}{|c|c|c|c|c|c|c|c|c|c|c|c|}
\hline & & Dissolved & & & & & & Particulate & Nitrate & Particulate & \\
\hline & Temperature & oxygen & $\mathrm{pH}$ & Conductivity & PAR & Turbidity & Chlorophyll & $\mathrm{N}$ & $\mathrm{N}$ & $\mathrm{P}$ & FRP \\
\hline$\overline{\mathrm{A} . \mathrm{CV} \%}$ & & & & & & & & & & & \\
\hline $0-10$ & 100.0 & 73.8 & 99.2 & 100.0 & 4.8 & 50.0 & 8.3 & & 41.7 & 58.3 & 66.7 \\
\hline $11-20$ & & 14.3 & 0.8 & & 3.2 & 16.7 & 25.0 & 8.3 & 8.3 & 25.0 & 25.0 \\
\hline $21-40$ & & 6.3 & & & 20.6 & 33.3 & 50.0 & 25.0 & 16.7 & 8.3 & 8.3 \\
\hline $41-80$ & & 5.6 & & & 34.9 & & 16.7 & 50.0 & 25.0 & 8.3 & \\
\hline $81-160$ & & & & & 33.3 & & & 16.7 & 8.3 & & \\
\hline $161-320$ & & & & & 3.2 & & & & & & \\
\hline B. Extre & mes & & & & & & & & & & \\
\hline Units & ${ }^{\circ} \mathrm{C}$ & $\%$ sat & $\mathrm{pH}$ & $\mu \mathrm{S} \mathrm{cm}^{-1}$ & $\mu \mathrm{mol} \mathrm{s}{ }^{-1} \cdot \mathrm{m}^{-2}$ & NTU & $\mu \mathrm{g} . \mathrm{L}^{-1}$ & $\mu \mathrm{g} . \mathrm{L}^{-1}$ & $\mu \mathrm{g} . \mathrm{L}^{-1}$ & $\mu \mathrm{g} . \mathrm{L}^{-1}$ & $\mu \mathrm{g} . \mathrm{L}^{-1}$ \\
\hline Basalt $R$ & & & & & & & & & & & \\
\hline Min & 17.9 & 0.7 & 6.8 & 55.0 & 0.1 & 1.4 & 0.4 & 5 & 2 & 2 & 1.0 \\
\hline Max & 34.0 & 122.1 & 10.2 & 1123.0 & 2221.0 & 61.4 & 58.7 & 413 & 8 & 88 & 18.0 \\
\hline Keelbottc & $m$ Ck. & & & & & & & & & & \\
\hline Min & 21.0 & 1.7 & 5.8 & 189 & 0.1 & 1.9 & 0.0 & 5 & 0.5 & 1 & 1.0 \\
\hline Max & 34.5 & 133.5 & 10.0 & 476.0 & 1419.3 & 51.1 & 151.9 & 136 & 4 & 39 & 13.0 \\
\hline Suttor $R$ & & & & & & & & & & & \\
\hline Min & 17.6 & 1.5 & 6.1 & 15.0 & 0.1 & 2.0 & 0.5 & 0.5 & 4 & 65 & 4.0 \\
\hline Max & 33.2 & 96.7 & 11.0 & 692.0 & 1796.3 & 747.5 & 230.4 & 555 & 217 & 374 & 12.0 \\
\hline
\end{tabular}

Table 3. Results of regression analyses of water-quality variables against putative explanatory large-scale variables, conductivity and turbidity; and results of DistLM analysis on combined water-quality data.

\begin{tabular}{|c|c|c|c|c|c|c|}
\hline & \multicolumn{2}{|c|}{ Conductivity } & \multirow[b]{2}{*}{$P$} & \multicolumn{2}{|c|}{ Turbidity } & \multirow[b]{2}{*}{$P$} \\
\hline & $r^{2}$ & $F$ & & $r^{2}$ & $F$ & \\
\hline \multicolumn{7}{|l|}{ Survey 1 (d.f. $=120)$} \\
\hline Temperature min & 0.060 & - & - & 0.012 & - & - \\
\hline Temperature max & 0.016 & - & - & $<0.01$ & - & - \\
\hline $\mathrm{pH}$ min & 0.152 & 21.3 & $<0.0001$ & $<0.01$ & - & - \\
\hline $\mathrm{pH} \max$ & 0.172 & 24.67 & $<0.0001$ & $<0.01$ & - & - \\
\hline $\mathrm{pH}$ max-min & 0.035 & 4.25 & 0.0414 & $<0.01$ & - & - \\
\hline $\mathrm{DO} \min$ & $<0.01$ & - & - & $<0.01$ & - & - \\
\hline DO max & 0.023 & - & - & $<0.01$ & - & - \\
\hline DO max-min & 0.010 & - & - & 0.002 & - & - \\
\hline Turbidity & 0.105 & 13.91 & 0.0003 & & & \\
\hline PAR max & 0.014 & - & - & $<0.01$ & - & - \\
\hline Chlorophyll & 0.115 & 15.5 & 0.0001 & 0.255 & 40.82 & $<0.0001$ \\
\hline Phaeophytin & 0.091 & 11.85 & 0.0008 & 0.144 & 20.04 & $<0.0001$ \\
\hline Overall (DistLM) & 0.065 & 8.23 & 0.001 & 0.043 & 5.31 & 0.003 \\
\hline \multicolumn{7}{|l|}{ Survey $2($ d.f. $=35)$} \\
\hline Particulate N & 0.110 & 4.22 & 0.048 & 0.183 & 7.63 & 0.0092 \\
\hline $\mathrm{NO}_{3}$ & 0.163 & 6.64 & 0.015 & 0.981 & 1765.8 & $<0.0001$ \\
\hline Particulate $\mathrm{P}$ & 0.143 & 5.67 & 0.023 & 0.966 & 956.93 & $<0.0001$ \\
\hline FRP & 0.02 & - & - & 0.134 & 5.28 & 0.0279 \\
\hline Overall (DistLM) & 0.109 & 4.17 & 0.017 & 0.566 & 44.36 & 0.001 \\
\hline
\end{tabular}

$F$ ( = pseudo- $F$ for DistLM) and $P$ shown only for relationships with $P<0.05$.

Keelbottom Creek (sourced from coastal mountains) or Basalt River (from basalt aquifers). Deterioration in water quality in these systems occurs naturally, as a result of persistent turbidity or evaporation, but anthropogenic impacts, such as water abstraction or contamination by cattle, may severely affect system integrity (Hamilton et al., 2005; Sheldon, 2005). There was no indication that the waterholes in this study were threatened by current land use, probably because their size buffers effects of cattle at the stocking densities obtaining during this study, suggesting that the waterholes are important ecological refugia, given the impacts caused by cattle elsewhere in the region (O'Reagain et al., 2005).

Although we sampled at several scales, this study was restricted to snapshots in time (5 out of about 24 months) and did not include "pre-flush" or "first flush" events (Davis et al., 2016) because of access difficulties, so variability is likely greater than we report. However, we 
demonstrated that variability in commonly recorded biophysical water-quality parameters needs to be carefully considered and reported in studies aiming to characterize sites and explain ecological patterns. Our study rivers could not be used as references for each other in river health assessment as they are so different, each requiring individual reference conditions (Norris and Thoms, 1999; Loong et al., 2005), and creating a challenge given that there are no parallel pristine systems (cf. Pearson et al., 2013). After wet-season flushing, isolated waterholes also require different reference conditions as they become increasingly influenced by local factors. Similar conclusions have been drawn for waterholes in Cooper Creek (McGregor et al., 2006) and for the invertebrate fauna of the Burdekin system (Blanchette and Pearson, 2012a).

Conductivity, diel DO, diel water temperature and water clarity are regarded as the most useful water-quality indicators in dryland rivers (Butler et al., 2009; Bunn et al., 2010). Our results largely agree, as conductivity separated rivers as a result of differences in lithology, diel DO indicated likely times of stress for aquatic organisms, and clarity, which influences photosynthesis, productivity and DO, varied substantially amongst sites. DO can vary more through the water column and over $24 \mathrm{~h}$ than across seasonal samples, in which case single grab samples are inadequate for capturing critical values. Local conditions can determine the impacts of contaminants: for example, a shaded waterhole may have low levels of photosynthesis and minor response to nutrient enrichment (Loong et al., 2005).

Burrows and Butler (2007) proposed two DO guidelines: a "chronic trigger value", below which sensitive organisms gradually suffer physiological effects; and an "acute trigger value", at which some species must employ unsustainable methods, such as air breathing, to avoid physiological effects. Our results indicate that detecting these triggers requires a sampling intensity that may be beyond many ecological studies because of logistic and funding constraints. Such studies should explicitly recognize this shortcoming, but should at least target the critical values experienced by species tied to particular habitats (e.g., benthos). We concur with Sheldon and Fellows (2010) that development of water-quality guidelines is hampered by the variability of dryland rivers and that guidelines should be developed with respect to the flow regime, as indicated in water-quality models for the GBR region (Davis et al., 2016). Appropriate spatial and temporal distribution of samples can only be achieved after strategic pilot studies targeting: (i) known variability in lithology and land use among catchments, (ii) among-site spatial variability, (iii) the flow regime and (iv) within-site spatial and temporal variability of key parameters.

\section{Supplementary material}

The supplementary material for this article can be found at http://dx.doi.org/10.1051/limn/2017008.
Acknowledgements. We thank our many volunteer assistants, landholders for granting access to study sites, and D. Burrows and K. Heiman for useful discussions. Water analysis was undertaken by the Australian Centre for Tropical Freshwater Research (now TropWater) at James Cook University. We also thank Dr Oleg Pokrovsky and two anonymous reviewers for their very constructive advice.

\section{References}

Anderson M.J., Gorley R.N. and Clarke K.R., 2008. PERMANOVA + for PRIMER: Guide to Software and Statistical Methods, PRIMER-E, Plymouth, UK.

Blanchette M.L. and Pearson R.G., 2012a. Macroinvertebrate assemblages in rivers of the Australian dry tropics are highly variable. Freshw. Sci., 31, 865-881.

Blanchette M.L. and Pearson R.G., 2012b. Dynamics of habitats and macroinvertebrate assemblages in rivers of the Australian dry tropics. Freshw. Biol., 58, 742-757.

Brodie J. and Mitchell A., 2005. Nutrients in Australian tropical rivers: changes with agricultural development and implication's for receiving environments. Mar. Freshw. Res., 56, 279-302.

Bunn S.E., Thoms M.C., Hamilton S.K. and Capon S.J., 2006. Flow variability in dryland rivers: boom, bust and the bits in between. River Res. Appl., 22, 179-186. doi: 10.1002/ rra.904.

Bunn S.E., Abal E.G., Smith M.J., Choy S.C., Fellows C.S. et al., 2010. Integration of science and monitoring of river ecosystem health to guide investments in catchment protection and rehabilitation. Freshw. Biol., 55, 223-240.

Burrows D.W. and Butler B.M., 2007. Determining end-point goals and effective strategies for rehabilitation of coastal wetlands: examples from the Burdekin River, north Queensland. In: Wilson A.L., Dehaan R.L., Watts R.J., Page K.J, Bowmer K.H. and Curtis A. (eds.), Proceedings of the 5th Australian Stream Management Conference. Australian Rivers: Making a Difference, Charles Sturt University, Albury, Australia, 49-54.

Butler B., Burrows D. and Loong D., 2009. Strategies for monitoring freshwater habitats in the Burdekin Dry Tropics NRM region to establish regional ambient water quality guidelines and assess the condition of wetlands in the lower Burdekin. Australian Centre for Tropical Freshwater Research Report No. 09/26, James Cook University, Townsville, Australia.

Clarke K.R. and Gorley R.N., 2006. PRIMER Version 6. User Manual/Tutorial, PRIMER-E Ltd, Plymouth, UK.

Davis A.M., Pearson R.G., Brodie J.E. and Butler, B., 2016. Review and conceptual models of agricultural impacts and water quality in tropical and sub-tropical waterways of the Great Barrier Reef catchment area. Mar. Freshw. Res. doi.org/10.1071/MF15301.

DeNicola D.M., de Eyto E., Wemaere A. and Irvine K., 2004. Using epilithic algal communities to assess trophic status in Irish lakes. J. Phycol., 40, 481-495.

Fabbro L.D. and Duivenvoorden L.J., 2000. A two-part model linking multidimensional environmental gradients and seasonal succession of phytoplankton assemblages. Hydrobiologia, 438, 13-24. 
Hamilton S.K., Bunn S.E., Thoms M.C. and Marshall J.C., 2005. Persistence of aquatic refugia between flow pulses in a dryland river system (Cooper Creek, Australia). Limnol. Oceanogr., 50, 743-754.

Jeffery S.W. and Humphrey G.F. (1975). New spectrophotometric equations for determining chlorophylls a, b, c1 and c2 in higher plants, algae and natural phytoplankton. Biochem. Physiol. Pflanzen, 167, 191-194.

Kennard M.J., Pusey B.J., Olden J.D., Mackay S.J., Stein J.L. and Marsh N., 2010. Classification of natural flow regimes in Australia to support environmental flow management. Freshw. Biol., 55, 171-193.

Leigh C. and Sheldon F., 2009. Hydrological connectivity drives patterns of macroinvertebrate biodiversity in floodplain rivers of the Australian wet/dry tropics. Freshw. Biol., 54, 549-571.

Loong D., Butler B., Burrows D., Davis A. and Faithful J., 2005. National Action Plan for salinity and water quality for the Burdekin catchment: priority action project no. 4. Limnological assessment and benchmarking of key sentinel wetlands in the Burdekin catchment, north Queensland. Australian Centre for Tropical Freshwater Research, Report No. 05/09, James Cook University, Townsville, Australia.

Marshall J.C., Sheldon F., Thoms M. and Choy S., 2006. The macro invertebrate fauna of an Australian dryland river: spatial and temporal patterns and environmental relationships. Mar. Freshw. Res., 57, 61-74.

McGregor G.B., Marshall J.C. and Thoms M.C., 2006. Spatial and temporal variation in algal-assemblage structure in isolated dryland river waterholes, Cooper Creek and Warrego River, Australia. Mar. Freshw. Res., 57, 453-466.

McJannet D., Marvane S., Kinsey-Henderson A., Petheram C. and Wallace J., 2014. Persistence of in-stream waterholes in ephemeral rivers of tropical northern Australia and potential impacts of climate change. Mar. Freshw. Res., 65, 1131-1144.

McKergow L.A., Prosser I.P., Hughes A.O. and Brodie J., 2005. Sources of sediment to the Great Barrier Reef World Heritage Area. Mar. Pollut. Bull., 51, 200-211.
Norris R.H. and Thoms M.C., 1999. What is river health? Freshw. Biol., 41, 197-209.

O'Reagain P.J., Brodie J., Fraser G., Bushell J.J., Holloway C.H., Faithful J.W. and Haynes D., 2005. Nutrient loss and water quality under extensive grazing in the upper Burdekin river catchment, North Queensland. Mar. Pollut. Bull., 51, 37-50.

Pearson R.G., Godfrey P.C., Arthington A.H., Wallace J., Karim F. and Ellison M., 2013. Biophysical status of remnant freshwater floodplain lagoons in the Great Barrier Reef catchment: a challenge for assessment and monitoring. Mar. Freshw. Res., 64, 208-222.

Pearson R.G., Connolly N.M. and Boyero L., 2015. Ecology of streams in a biogeographic isolate - the Queensland Wet Tropics, Australia. Freshw. Sci., 34, 797-819.

Pettit N.E., Jardine T.D., Hamilton S.K., Sinnamon V., Valdez D., Davies P.M., Douglas M.M. and Bunn S.E., 2012. Seasonal changes in water quality and macrophytes and the impact of cattle on tropical floodplain waterholes. Mar. Freshw. Res., 63, 788-800.

QDNRM (Queensland Department of Natural Resources and Mines), 2002. Water Supply Planning Study Report: Burdekin Basin Draft Water Resource Plan, Queensland Government, Brisbane, Australia.

Sheldon F., 2005. Incorporating natural variability into the assessment of ecological health in Australian dryland rivers. Hydrobiologia, 552, 45-56.

Sheldon F. and Fellows C.S., 2010. Water quality in two Australian dryland rivers: spatial and temporal variability and the role of flow. Mar. Freshw. Res., 61, 864-874.

Sheldon F., Bunn S.E., Hughes J.M., Arthington A.H., Balcombe S.R. and Fellows C.S., 2010. Ecological roles and threats to aquatic refugia in arid landscapes: dryland river waterholes. Mar. Freshw. Res., 61, 885-895.

Wallace J., Waltham N., Burrows D. and McJannet D., 2015. The temperature regimes of dry-season waterholes in tropical northern Australia: potential effects on fish refugia. Freshw. Sci., 34, 663-678. 